\title{
EXPERIMENTAL DAMAGE IDENTIFICATION BY APPLYING STRUCTURAL DYNAMIC MODEL UPDATING
}

\author{
SHANKAR SEHGAL*, HARMESh KUMAR \\ Mechanical Engineering, UIET, Panjab University, Chandigarh, \\ 160014 India
}

[Received 02 January 2018. Accepted 18 February 2019]

doi: 10.7546/JTAM.49.19.01.05

\begin{abstract}
In this paper, structural dynamic model updating has been utilized in experimentally evaluating the extent of damage at six locations of a damaged cantilever beam structure. Six elements of the beam had lateral cuts. These cuts resulted in unknown reductions in flexural rigidity parameters. These parameters were taken as updating parameters and the reductions in these parameters were identified through dynamic model updating and evaluated to be $54.49,100.09,79.63,82.17,45.60$ and $27.40 \mathrm{Nm}^{2}$. Updated finite element model of the structure was created by incorporating reduced flexural rigidity parameters. Dynamic results of updated model showed that total absolute error in prediction of natural frequencies was reduced by $98.36 \%$, which confirmed accurate identification of flexural rigidity parameters and hence damage extents in the beam.
\end{abstract}

KEY WORDS: damage identification; structural dynamics; model updating; response surfaces; modal testing.

\section{INTRODUCTION}

Damage identification in structural dynamics is an inverse problem in which modelupdating is used to identify correct values of physical parameters of Finite Element (FE) model in such a way to reduce the mismatch between experimental and analytical dynamic responses. These dynamic responses such as natural frequencies can be obtained experimentally as well as theoretically $[1,2]$. Theoretical route is based on the use of classical method [3] or FE method [4]. FE model generally does not incorporate the damages /cuts/ cracks present in real life structures. In such situations, FE model becomes incapable to predict accurate dynamic responses. Thus there is a need to estimate the damages and also to correct/update the FE model so that its theoretical responses correlate well with the experimental responses. This process of correcting the FE model is called structural dynamic model updating [5-8]. Model updating techniques are either direct or iterative techniques. Direct techniques

\footnotetext{
${ }^{*}$ Corresponding author e-mail: sehgals@pu.ac.in
} 
are the one step techniques such as those proposed by Baruch and Bar-Itzhack [9], Baruch [10], Berman [11], Berman and Nagy [12]. Updated system matrices produced by direct techniques may not be symmetric and positive definite, therefore, these techniques are not preferred in industry. Industrial applications generally employ iterative updating techniques such as those proposed by Collins et al. [13], Lin and Ewins [14], Atalla and Inman [15], Li [16], Lin and Zhu [17], Arora et al. [18, 19] and Silva [20]. Later, a new iterative technique was introduced by Sehgal and Kumar [21]. This technique used Response Surface (RS) models [22] and Derringer's function method [23] in formulation of objective functions. In this technique, updating was treated as multi-objective optimization problem with an aim to minimize errors in prediction of natural frequencies.

Sehgal and Kumar [21] applied their updating technique to a numerical case study only, during which simulated results were taken as targets instead of actual experimental results. However in this work, actual modal testing of a real life damaged beam was carried out to measure experimental dynamic responses. Experimentally obtained natural frequencies were taken as targets. Flexural rigidity parameters of damaged elements were taken as updating parameters and were evaluated through RS models based model updating method. Modified flexural rigidity parameters were further used to develop corrected FE model which predicts the natural frequencies of the structure with total absolute error of just $1.04 \%$ compared to $63.37 \%$ error level exhibited earlier by the un-updated FE model.

\section{Materials And Methods}

Cantilever beam used during this work was of mild steel with dimensions $540 \times 49 \times$ $6 \mathrm{~mm}^{3}$, density of $7696 \mathrm{~kg} / \mathrm{m}^{3}$ and Young's modulus of elasticity as $210 \mathrm{GPa}$. For testing purpose, the beam was supposed to be divided into twelve elements of equal size. Cuts in lateral direction were then imparted by using a hacksaw on first six elements near fixed end of the beam. Thus a damaged cantilever beam set-up was developed wherein the extents of damages were not known initially.

As shown in Fig. 1, the experimental set-up consisted of an impulse hammer, accelerometer, Fast Fourier Transformer (FFT) analyzer and a computer interface with signal processing software. Figure 2 shows the FE model of the experimental beam that was created in Matlab ${ }^{\circledR}$ [24]. It had total 12 elements; half of which were damaged ones. Flexural rigidity parameters $\left(K_{1}, K_{2}, K_{3}, K_{4}, K_{5}\right.$ and $\left.K_{6}\right)$ of the damaged elements were unknown and taken as updating parameters. Initially, these parameters were taken as $185.22 \mathrm{Nm}^{2}$, which was same as that of undamaged elements of the beam. Due to non-consideration of damage effects into the FE model, its predicted natural frequencies were far away from measured natural frequencies as shown in Table 1. 


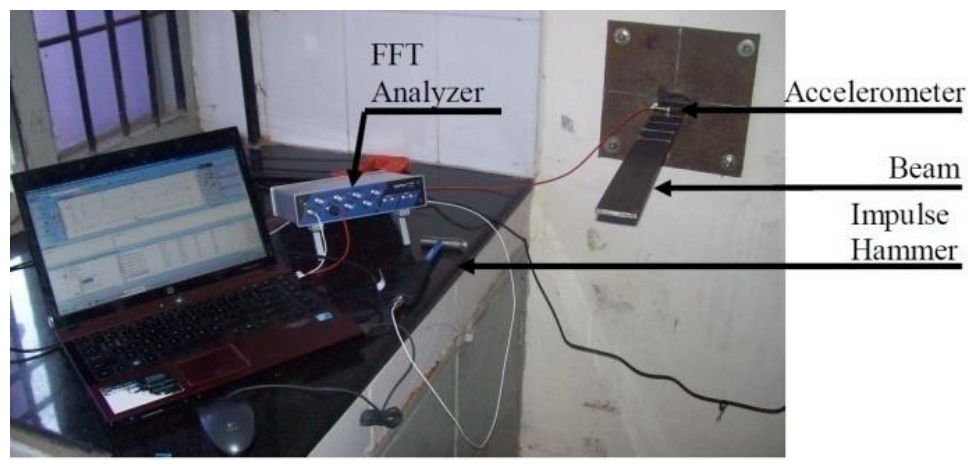

Fig. 1. (Color online) Experimental set-up.

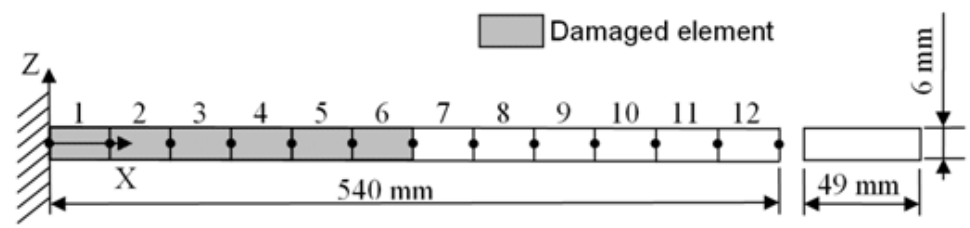

Fig. 2. FE model of the beam structure.

After having obtained the experimental and FE natural frequencies, next step was to form an experimental design matrix as per D-optimal design method by using Design-Expert ${ }^{\circledR}$ software [25]. While developing the experimental design matrix, lower limit for flexural rigidity parameters of damaged elements was set to be $74.09 \mathrm{Nm}^{2}$, i.e., 0.4 times $185.22 \mathrm{Nm}^{2}$, where $185.22 \mathrm{Nm}^{2}$ is the value of flexural rigidity of undamaged beam. Upper limit for flexural rigidity parameters was taken as $166.70 \mathrm{Nm}^{2}$, i.e., 0.9 times $185.22 \mathrm{Nm}^{2}$. Coded parameters $A, B, C, D, E$ and $F$ were defined in such a way that they varied linearly between -1 and +1 over the complete range of the updating parameters $K_{1}, K_{2}, K_{3}, K_{4}, K_{5}$ and $K_{6}$ respec-

Table 1. Comparison of dynamic responses before updating

\begin{tabular}{ccc}
\hline \hline $\begin{array}{c}\text { Mode } \\
\text { number }\end{array}$ & $\begin{array}{c}\text { Experimental natural frequency } \\
(\mathrm{Hz})\end{array}$ & $\begin{array}{c}\text { FE natural frequency before updating } \\
(\mathrm{Hz})\end{array}$ \\
\hline 1 & 13.50 & 17.36 \\
2 & 97.50 & 108.81 \\
3 & 273.30 & 304.71 \\
4 & 534.80 & 597.32 \\
\hline \hline
\end{tabular}


tively. Experimental design matrix was then used to produce corresponding data set for response variables.

Regression along with backward elimination based ANalysis of VAriance (ANOVA) was used to prepare RS models for first four natural frequencies [26]. Individual desirability functions were formed by using two-sided transformation method of Derringer's function approach [23] as per (1) by taking target values, lower limits and upper limits mentioned in Table 2. Through this, the physical problem of model updating was converted to a dimensionless mathematical multi-objective optimization problem, wherein, all individual desirability functions were required to be maximized; the maximum possible value of any individual desirability function being unity.

$$
d_{i}= \begin{cases}{\left[\frac{\hat{\omega}_{i}-\hat{\omega}_{i L L}}{\hat{\omega}_{i T}-\hat{\omega}_{i L L}}\right],} & \hat{\omega}_{i L L} \leq \hat{\omega}_{i} \leq \hat{\omega}_{i T} \\ {\left[\frac{\hat{\omega}_{i U L}-\hat{\omega}_{i}}{\hat{\omega}_{i U L}-\hat{\omega}_{i T}}\right],} & \hat{\omega}_{i T}<\hat{\omega}_{i} \leq \hat{\omega}_{i U L} \\ 0, & \hat{\omega}_{i}<\hat{\omega}_{i L L} \text { or } \hat{\omega}_{i}>\hat{\omega}_{i U L}\end{cases}
$$

where, $d_{i}$ is $i^{\text {th }}$ individual desirability function; $\hat{\omega}_{i}$ is RS predicted natural frequency of $i^{\text {th }}$ mode; $\hat{\omega}_{i L L}, \hat{\omega}_{i T}, \hat{\omega}_{i U L}$ are respectively the lower limit, target value and upper limit of $\hat{\omega}_{i}$.

Table 2. Formation of individual desirability functions

\begin{tabular}{cccc}
\hline \hline Parameter & Target value $(\mathrm{Hz})$ & Lower limit $(\mathrm{Hz})$ & Upper limit $(\mathrm{Hz})$ \\
\hline$\hat{\omega}_{1}$ & 13.50 & 6.75 & 20.25 \\
$\hat{\omega}_{2}$ & 97.50 & 48.75 & 146.25 \\
$\hat{\omega}_{3}$ & 273.30 & 136.65 & 409.95 \\
$\hat{\omega}_{4}$ & 534.80 & 267.40 & 802.20 \\
\hline \hline
\end{tabular}

Overall desirability function was formed as per (2) in order to convert the complex FE updating problem to a single objective optimization type. The sole objective of solving the problem was to maximize the overall desirability function $D_{0}$.

$$
D_{0}=\left(d_{1} \times d_{2} \times d_{3} \times \cdots \times d_{n}\right)^{1 / n},
$$

where, $D_{0}$ is overall desirability function; $d_{n}$ is $n^{\text {th }}$ individual desirability function; $n$ is number of dynamic responses. In this work, value of $n$ was taken as four because first four natural frequencies were considered during updating. 
Maximum value of overall desirability function was then searched out, which was further used to find out the updated values of flexural rigidity parameters of damaged elements. Updated values of these parameters were then used to produce an updated FE model and hence updated natural frequencies. Updated natural frequencies were then compared with their experimental counterparts to check for prediction errors. It was observed that total absolute error in prediction of natural frequencies was reduced from $63.37 \%$ before updating to just $1.04 \%$ after updating thereby confirming the accuracy of formulation of updated FE model. Accurate FE model formulation reveals accurate estimation of flexural rigidity parameters of damaged elements of the beam and hence accurate damage identification.

\section{Results AND Discussion}

Figure 3 shows a comparison of FE and experimental frequency response functions obtained from Matlab ${ }^{\circledR}$ and modal testing respectively before updating. Clearly there is a mismatch of natural frequencies. This mismatch is attributed to the presence of unknown damages in actual structure which were not taken into account by the FE model before updating.

For updating purpose, RS models of the beam were created and tested for significance by performing backward elimination based ANOVA [26] in Table 3. As per Table 3, RS model for $\hat{\omega}_{1}$ was found to be statistically significant. Polynomial equation for RS predicted first natural frequency was derived to be as per (3). ANOVA for next three natural frequencies were also performed as per procedure discussed earlier for first natural frequency. Polynomial equations for second, third and fourth natural frequencies have been provided in (4), (5) and (6), respectively.

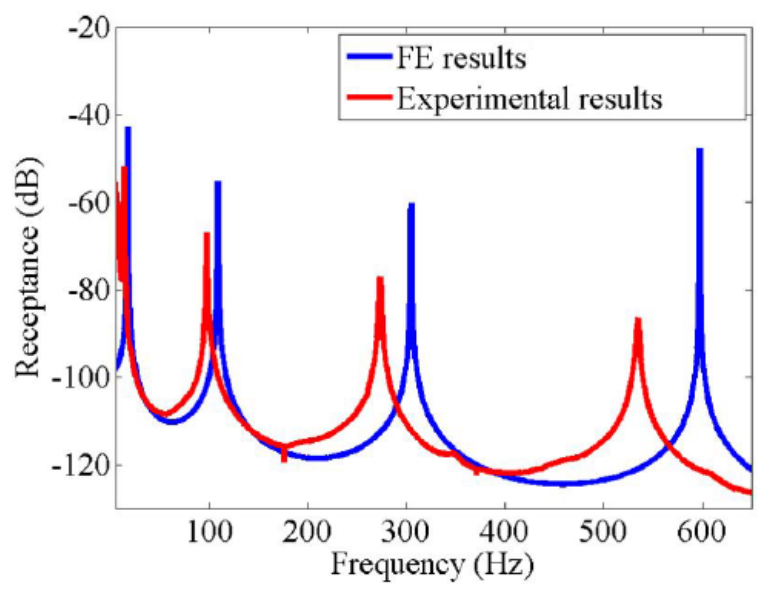

Fig. 3. (Color online) Comparison of FE and experimental receptance before updating. 
(3) $\hat{\omega}_{1}=14.10+0.80 A+0.63 B+0.46 C+0.34 D+0.23 E+0.14 F$

$+0.11 A B+0.08 A C+0.06 A D+0.05 A E+0.02 A F+0.06 B C$

$+0.04 B D+0.03 B E+0.02 C D+0.02 C E-0.22 A^{2}-0.23 B^{2}$

$-0.23 C^{2}-0.10 D^{2}-0.10 E^{2}$,

(4) $\hat{\omega}_{2}=95.42+4.46 A+1.19 B+0.14 C+0.93 D+2.51 E+3.73 F$

$+0.61 A B-0.18 A D-0.09 A E+0.15 A F+0.05 B C-0.07 B D$

$-0.11 B E+0.05 C F+0.19 D E+0.20 D F+0.45 E F-1.00 A^{2}$

$-0.31 B^{2}-0.36 D^{2}-0.88 E^{2}-1.17 F^{2}$,

(5) $\quad \hat{\omega}_{3}=275.01+8.55 A+0.78 B+4.22 C+7.28 D+3.74 E+0.60 F$

$+0.21 A B-0.84 A C+0.17 A D+0.70 A E+0.89 C D+0.66 C E$

$+0.15 C F+1.01 D E-1.37 A^{2}-1.63 C^{2}-2.23 D^{2}-1.24 E^{2}$,

(6) $\hat{\omega}_{4}=531.31+13.47 A+4.91 B+14.96 C+5.65 D+5.02 E$

$+18.03 F-1.37 A B+1.18 A D-0.66 A E+1.58 B C+0.80 B D$

$+2.46 C D-1.13 C E+0.58 C F-0.74 D E-0.42 D F+2.01 E F$

$-1.83 A^{2}-1.32 B^{2}-3.68 C^{2}-1.60 D^{2}-1.79 E^{2}-4.53 F^{2}$.

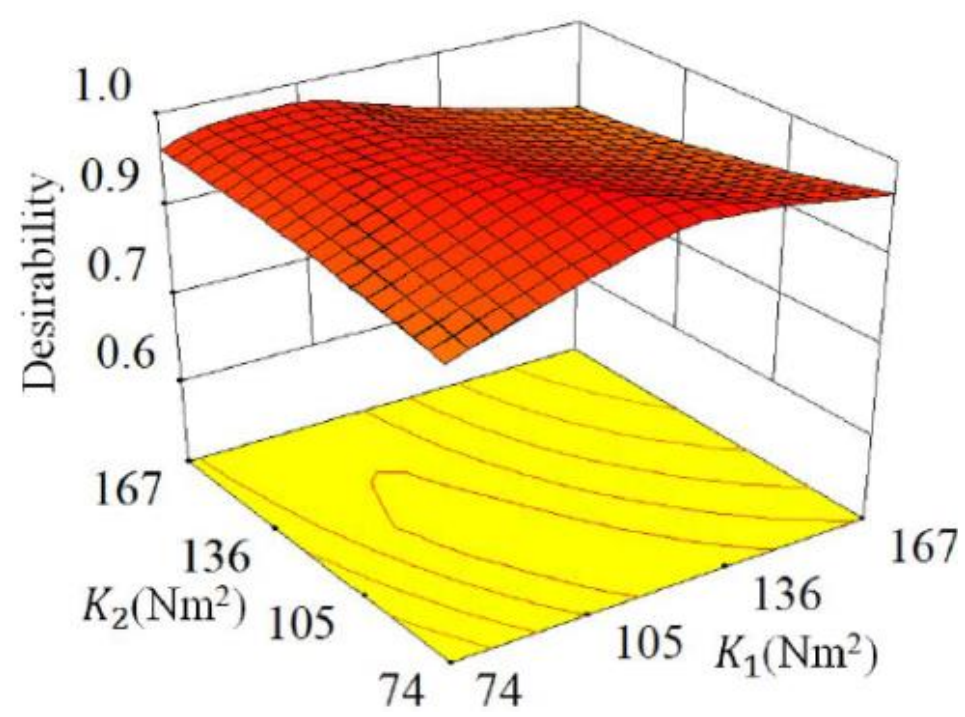

Fig. 4. (Color online) Surface plot of overall desirability function ( $K_{1}$ : flexural rigidity of first element; $K_{2}$ : flexural rigidity of second element). 
Experimental Damage Identification by Applying Structural Dynamic ...

Table 3. ANOVA for RS predicted first natural frequency

\begin{tabular}{cccccc}
\hline \hline Source & $\begin{array}{c}\text { Sum of } \\
\text { squares }\end{array}$ & $\begin{array}{c}\text { Degrees of } \\
\text { freedom }\end{array}$ & $\begin{array}{r}\text { Mean } \\
\text { square }\end{array}$ & F-Value & p-value \\
\hline Model & 64.73 & 21 & 3.08 & 1488.58 & $<0.0001$ \\
$A$ & 25.61 & 1 & 25.61 & 12369.36 & $<0.0001$ \\
$B$ & 16.26 & 1 & 16.26 & 7853.13 & $<0.0001$ \\
$C$ & 8.69 & 1 & 8.69 & 4195.95 & $<0.0001$ \\
$D$ & 4.76 & 1 & 4.76 & 2299.67 & $<0.0001$ \\
$E$ & 2.09 & 1 & 2.09 & 1008.74 & $<0.0001$ \\
$F$ & 0.77 & 1 & 0.77 & 371.64 & $<0.0001$ \\
$A B$ & 0.45 & 1 & 0.45 & 215.98 & $<0.0001$ \\
$A C$ & 0.24 & 1 & 0.24 & 117.36 & $<0.0001$ \\
$A D$ & 0.14 & 1 & 0.14 & 68.83 & $<0.0001$ \\
$A E$ & 0.08 & 1 & 0.08 & 37.01 & $<0.0001$ \\
$A F$ & 0.01 & 1 & 0.01 & 6.26 & 0.0182 \\
$B C$ & 0.13 & 1 & 0.13 & 64.84 & $<0.0001$ \\
$B D$ & 0.06 & 1 & 0.06 & 30.02 & $<0.0001$ \\
$B E$ & 0.04 & 1 & 0.04 & 17.98 & 0.0002 \\
$C D$ & 0.02 & 1 & 0.02 & 9.83 & 0.0039 \\
$C E$ & 0.02 & 1 & 0.02 & 9.33 & 0.0048 \\
$A^{2}$ & 0.27 & 1 & 0.27 & 131.40 & $<0.0001$ \\
$B^{2}$ & 0.24 & 1 & 0.24 & 116.21 & $<0.0001$ \\
$C^{2}$ & 0.25 & 1 & 0.25 & 119.84 & $<0.0001$ \\
$D^{2}$ & 0.05 & 1 & 0.05 & 25.89 & $<0.0001$ \\
$E^{2}$ & 0.06 & 1 & 0.06 & 30.65 & $<0.0001$ \\
\hline Residual & 0.06 & 29 & 0.00 & & \\
Cor Total & 64.79 & 50 & & & \\
\hline Standard deviation & $=0.0455$ & & & $R^{2}=0.9991$ & \\
Mean 13.3646 & & & & Adjusted & 0.9984 \\
Coefficient of variation & 0.3405 & Predicted $R^{2}=0.9972$ \\
Predicted residual error sum of squares & 0.1817 & & Adequate precision $=162.9379$ \\
\hline \hline
\end{tabular}

Figure 4 shows the RS plot of the overall desirability function, wherein the highest peak value was observed to be 1.00 corresponding to the updating parameters $K_{1}$, $K_{2}, K_{3}, K_{4}, K_{5}$ and $K_{6}$ as $130.73,85.13,105.59,103.05,139.62$ and $157.82 \mathrm{Nm}^{2}$, respectively. It is clear that flexural rigidity of damaged elements is far less than that of the undamaged elements. Percent reduction in flexural rigidity of the six damaged elements is drawn in Fig. 5. Percent reduction in flexural rigidity and hence the extent of damage is highest in second element. This is followed by fourth, third, first, fifth and sixth element. Updated values of the flexural rigidity parameters were 


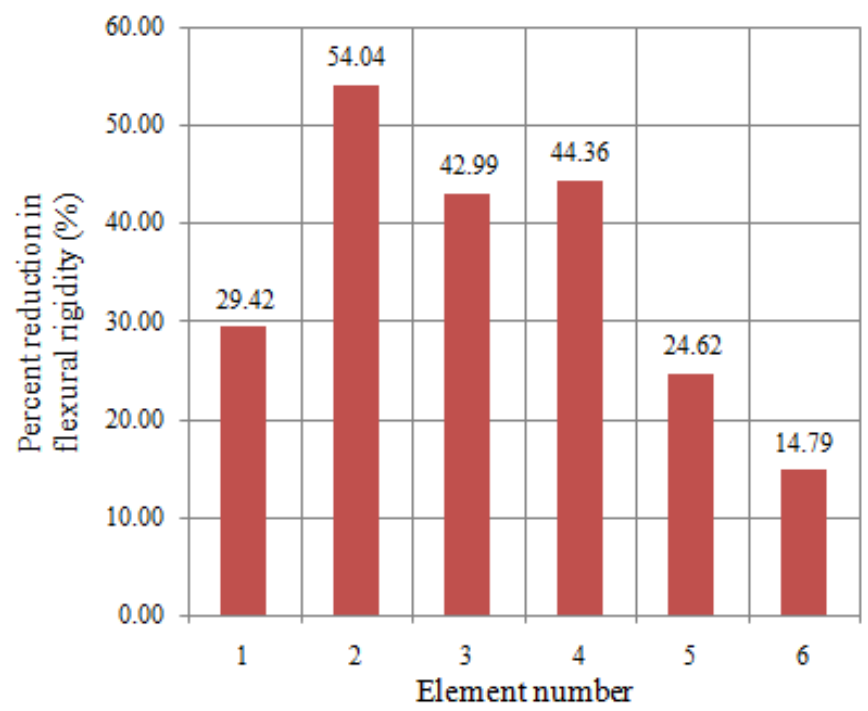

Fig. 5. (Color online) Results of percent reduction in flexural rigidity of damaged elements.

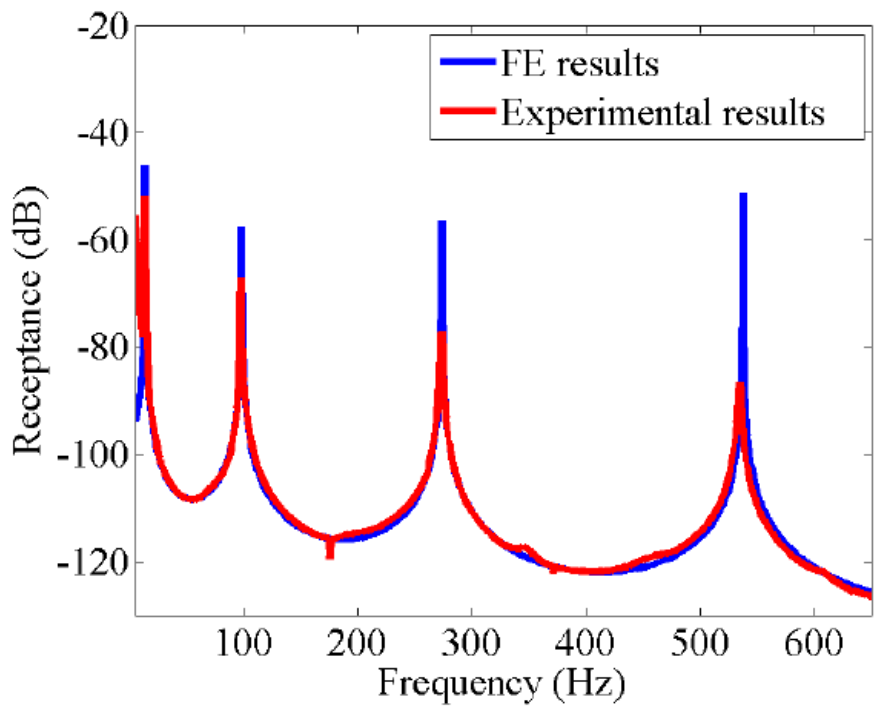

Fig. 6. (Color online) Comparison of FE and experimental receptance after updating.

then used to produce correct FE model; which was processed in Matlab $₫$ to produce updated frequency response functions and natural frequencies. Figure 6 shows a comparison of updated FE and experimental frequency response functions. Updated 
Experimental Damage Identification by Applying Structural Dynamic ...

Table 4. Comparison of dynamic responses before and after updating

\begin{tabular}{cccccc}
\hline \hline $\begin{array}{c}\text { Mode } \\
\text { number }\end{array}$ & $\begin{array}{c}\text { Experimental } \\
\text { natural } \\
\text { frequency } \\
(\mathrm{Hz})\end{array}$ & $\begin{array}{c}\text { FE natural } \\
\text { frequency before } \\
\text { updating } \\
(\mathrm{Hz})\end{array}$ & $\begin{array}{c}\text { Initial } \\
\text { absolute } \\
\text { error } \\
(\%)\end{array}$ & $\begin{array}{c}\text { FE natural } \\
\text { frequency after } \\
\text { updating } \\
(\mathrm{Hz})\end{array}$ & $\begin{array}{c}\text { Final } \\
\text { absolute } \\
\text { error } \\
(\%)\end{array}$ \\
\hline 1 & 13.50 & 17.36 & 28.59 & 13.50 & 0.00 \\
2 & 97.50 & 108.81 & 11.60 & 97.96 & 0.47 \\
3 & 273.30 & 304.71 & 11.49 & 273.48 & 0.07 \\
4 & 534.80 & 597.32 & 11.69 & 537.45 & 0.50 \\
\hline Total absolute error & & 63.37 & & 1.04 \\
Error reduction $(\%)$ & & & & 98.36 \\
\hline \hline
\end{tabular}

FE and experimental natural frequencies have been compared in Table 4. Before updating, there was total absolute error of $63.37 \%$ in prediction of natural frequencies of first four modes, which was minimized to $1.04 \%$ after updating thereby proving that the damages have been accurately detected and incorporated in the FE model of beam structure.

\section{CONClusion}

Damage identification was successfully performed by evaluating percent reduction in flexural rigidity of six damaged elements of an actual beam. Maximum damage occurred in second element; while minimum damage occurred in sixth element. This is supported by the fact that depth of cut was maximum in second and minimum in sixth element of the beam. Final updating results show that prediction errors in natural frequencies were reduced by $98.36 \%$ considering first four modes of vibration, thereby confirming the success of the method in evaluating accurate damage identification.

\section{ACKNOWLEDGMENTS}

Authors are thankful to University Grants Commission of New Delhi, India for providing the financial support for this research work vide major research project grant F. No. 42-869/2013(SR).

\section{REFERENCES}

[1] N.M.M. MaiA, J.M.M. Silva (1997) "Theoretical and Experimental Modal Analysis”. Research Studies Press Limited, England.

[2] D.J. EwINS (2000) "Modal Testing: Theory, Practice and Application". Research Studies Press Limited, England. 
[3] J.P. Den Hartog (1934) "Mechanical Vibrations". McGraw-Hill Book Company, Inc., USA.

[4] M. Petyt (1998) "Introduction to Finite Element Vibration Analysis”. Cambridge University Press, UK.

[5] M.I. Friswell, J.E. Mottershead (1995) "Finite Element Model Updating in Structural Dynamics". Kluwer Academic Publishers, The Netherlands.

[6] M. Imregun, W.J. Visser (1991) A Review of Model Updating Techniques. The Shock and Vibration Digest 23 141-162.

[7] J.E. Mottershead, M.I. Friswell (1993) Model Updating in Structural Dynamics: A Survey. Journal of Sound and Vibration 167(2) 347-375.

[8] S. Sehgal, H. Kumar (2016) Structural Dynamic Model Updating Techniques: A State of The Art Review. Archives of Computational Methods in Engineering 23 515533.

[9] M. BARUCH, I.Y. BAR-ITZHACK (1978) Optimal Weighted Orthogonalization of Measured Modes. AIAA Journal 16(4) 346-351.

[10] M. BARUCH (1978) Optimization Procedure to Correct Stiffness and Flexibility Matrices Using Vibration Tests. AIAA Journal 16(11) 1208-1210.

[11] A. BERMAN (1979) Mass Matrix Correction Using An Incomplete Set of Measured Modes. AIAA Journal 17 1147-1148.

[12] A. BERMAN, E.J. NAGY (1983) Improvement of A Large Analytical Model Using Test Data. AIAA Journal 21(8) 1168-1173.

[13] J.D. Collins, G.C. Hart, T.K. Hasselman, B. Kennedy (1974) Statistical Identification of Structures. AIAA Journal 12(2) 185-190.

[14] R.M. LIN, D.J. EwIns (1990) Model Updating Using FRF Data. In: Proceedings of the 15th International Seminar on Modal Analysis, Belgium, 1 pp. 141-163.

[15] M.J. Atalla, D.J. Inman (1998) On Model Updating Using Neural Networks. Mechanical Systems and Signal Processing 12(1) 135-161.

[16] W.L. Li (2002) A New Method For Structural Model Updating And Joint Stiffness Identification. Mechanical Systems and Signal Processing 16(1) 155-167.

[17] R.M. Lin, J. ZHU (2007) Finite Element Model Updating Using Vibration Test Data Under Base Excitation. Journal of Sound and Vibration 303 596-613.

[18] V. Arora, S.P. Singh, T.K. Kundra (2009) Finite Element Model Updating With Damping Identification. Journal of Sound and Vibration 324 1111-1123.

[19] V. Arora, S.P. Singh, T.K. Kundra (2009) Damped Model Updating Using Complex Updating Parameters. Journal of Sound and Vibration 320 438-451.

[20] S. DA Silva (2011) Non-Linear Model Updating of A Three-Dimensional Portal Frame Based on Wiener Series. International Journal of Non-Linear Mechanics 46 312-320.

[21] S. Sehgal, H. Kumar (2014) Structural Dynamic Finite Element Model Updating Using Derringer's Function: A Novel Technique. WSEAS Transactions on Applied and Theoretical Mechanics 9 11-26. 
Experimental Damage Identification by Applying Structural Dynamic ...

[22] R.H. Myers, D.C. Montgomery (1995) "Response Surface Methodology: Process and Product Optimization Using Designed Experiments". John Wiley and Sons (Asia) Private Limited, Singapore.

[23] G. Derringer, R. Suich (1980) Simultaneous Optimization of Several Response Variables. Journal of Quality Technology 12(4) 214-219.

[24] MATLAB ${ }^{\circledR}$ (2004) “User's guide of MATLAB” v7. The Mathworks Incorporation, New York.

[25] DESIGN-EXPERT ${ }^{\circledR}$ (2010) “User's Guide for Version 8 of Design-Expert. Stat-Ease Incorporation, Minneapolis, $\mathrm{MN}$.

[26] D.C. Montgomery, E.A. Peck, G.G. Vining (2003) "Introduction to Linear Regression Analysis". John Wiley and Sons (Asia) Private Limited, Singapore. 